\title{
Decreased Pump Speed
}

National Cancer Institute

\section{Source}

National Cancer Institute. Decreased Pump Speed. NCI Thesaurus. Code C63252.

Unintended decrease in pump speed and subsequent flow rate, compromising the intended function of a medical device. 